\title{
Transformer Bushing Damage Accident Analysis
}

\author{
Su Hainan ${ }^{1}$, Yan Shijie ${ }^{2}$, Chen Runjing ${ }^{1}$, Jiang Ling ${ }^{1}$, Zhang Wei ${ }^{3}$, Liu Xiao ${ }^{3}$, Guo Yan ${ }^{3}$, Wei \\ Ye $^{3}$, Cao Huijie ${ }^{3}$, Tong Xiaotong ${ }^{3}$ \\ ${ }^{1}$ State Grid Liaoning Electric Power Co., Ltd. Dandong power supply company. \\ ${ }^{2}$ State Grid Beijing Power Co., Ltd. \\ ${ }^{3}$ State Grid Liaoning Electric Power Co., Ltd. Fushun power supply company.
}

Keywords: Main transformer, Oil chromatographic analysis, The porcelain sleeve, Bushing

\begin{abstract}
Through the search for penetration cracks in the lower bushing of the main bushing, the effectiveness of the combination of oil chromatography and electrical testing is demonstrated. The structure and composition of the main transformer bushing and the common discharge forms and locations are introduced in detail. The main fault location where the low energy discharge occurs may be the bushing, winding, main transformer core or tap changer. Scientific means to conduct a one-by-one investigation. Finally, the low-energy discharge failure caused by the penetrating crack of the lower bushing of the bushing is concluded, and the repair time of the main transformer is shortened. Because of the bushing failure type of paper is very little, analysis methods and steps of the search bushing fault has left valuable experience. This has a certain reference value.
\end{abstract}

\section{Introduction}

Main transformer (hereinafter referred to as transformer): is the core power supply equipment of substation. It is composed of five parts: transformer body, fuel tank, protection device, cooling system and outlet bushing. electromagnetic energy conversion.

Fuel tank: the fuel tank is composed of mainly box body, box cover, bottom of box, attachment (oil valve, oil type valve, drain plug, ground bolt, etc.).

Protection device: the protection device is composed of oil storage tank, oil level gauge, oil purifier, flow relay, moisture absorber, signal thermometer, etc.

Cooling system: the cooling system is composed of coolers, submersible pumps of oil and ventilators.

Bushingis the lead out wire of the transformer winding must pass through the insulation bushing, which should be insulated between the lead out wires and between the lead out wire and the transformer shell, and it plays the role of fixing the lead wire.

The bushing is one of the most important components of the transformer, it includes oil filled bushing (for $35 \mathrm{kV}$ transformer), dry bushing (for $10 \mathrm{kV}$ transformer) and oil-immersed capacitor bushing (for $66 \mathrm{kV}$ and above). The bushing is also one of the current-carrying element, load current and short-time over current will be used for long term operation of transformers, so it must have good thermal stability to withstand the instantaneous overheating of the short circuit. The main form of bushing accident is dampness of capacitor core and main insulation breakdown, flashover of external insulation in rain, joint overheating and poor sealing, discharge, shedding and end shield bad grounding of uniform pressure ball, upper and lower porcelain sleeve rupture, oil leakage, etc. If the transformer bushing has defects or faults, the transformer's safe operation and its power supply reliability will be directly endangered.

\section{Bushing Failure Statistics}

\subsection{Bushing Failure Types}

In recent years, the accident rate of high-voltage bushings in operation has been on the rise. Typical bushing failure statistics are shown in Table I. 


\subsection{Cause of bushing accident}

Bushing failure is mainly caused by poor structure or manufacturing process and poor installation process; external insulation of porcelain bushing produces the rain flashover in bad environment; bad grounding of end screen causes oil chromatography to exceed the standard; in the long run, the aging crack of the sealing washer causes oil leakage and seepage; maintenance is not in place, resulting in through cracks on the upper and lower bushing of the bushing, losing insulation performance, and seriously even bushing explosion. Therefore, we should strengthen the monitoring of the running bushing, make timely maintenance, maintenance and test, and take precautionary measures in advance to ensure the safe operation of the equipment.

Table I Typical failure statistics of bushing

\begin{tabular}{|c|c|}
\hline Fault type & Failure performance \\
\hline $\begin{array}{c}\text { Partial } \\
\text { Discharge }\end{array}$ & $\begin{array}{l}\text { (1) Partial discharge in inflatable cavities will be caused by paper wetting, } \\
\text { incomplete impregnation, oil supersaturation, or paper contamination by } \\
\text { X- wax deposits. } \\
\text { (2) The loose insulation paper is broken and broken to cause partial } \\
\text { discharge during transportation. }\end{array}$ \\
\hline $\begin{array}{l}\text { Low } \\
\text { energy } \\
\text { discharge }\end{array}$ & $\begin{array}{l}\text { (1) Capacitance at the end of the screen caused by the spark discharge is } \\
\text { not working. } \\
\text { (2) Electrostatic shielding the arc in the connecting line. } \\
\text { (3) There is a discharge along the surface of the paper. } \\
\text { (4) A penetrating crack or even a crack occurs in the upper and lower } \\
\text { porcelain sleeves. The insulation performance is lost, and the bushing } \\
\text { explosion is even occurred in serious cases. }\end{array}$ \\
\hline $\begin{array}{l}\text { High } \\
\text { energy } \\
\text { discharge }\end{array}$ & $\begin{array}{l}\text { Short-circuit between capacitor-balanced metal foils, local high current } \\
\text { density can melt metal foil. But it doesn't cause the bushing to explode. }\end{array}$ \\
\hline $\begin{array}{l}\text { Heat fault } \\
300^{\circ} \mathrm{C}<\mathrm{t}< \\
700^{\circ} \mathrm{C}\end{array}$ & $\begin{array}{l}\text { (1) The high dielectric loss is caused by unreasonable selection of } \\
\text { pollution or insulation material, resulting in circulation in paper insulation } \\
\text { and thermal breakdown. } \\
\text { (2) Poor contact between bushing shields or high voltage leads. }\end{array}$ \\
\hline
\end{tabular}

\section{Bushing Structure Composition}

It is necessary to understand the structure of the bushing, especially the insulation structure, because the reliability of the operation is directly affected by it, and it also provides a theoretical basis for the discovery and discharge of defects in the test. In particularly, the bushing is made up of wiring terminal, oil storage cabinet, upper porcelain sleeve, lower porcelain sleeve, capacitor core, conductive tube, insulating oil, flange, grounded small bushing, voltage tap and uniform pressure ball, etc. As shown in Figure 1

Introduction to the important parts of the bushing:

(1) The outer insulation of the bushing is usually divided into the upper and lower porcelain sleeves, which require a high specific creepage distance, good sealing, high insulation, the required electrical strength and sufficient mechanical strength.

(2) The inner insulation is a cylindrical capacitor core. The copper conductive tube in the center of the cylinder is both the skeleton of the capacitor core and the leading wire hole used for passing through the leading-in cable (through the cable type). The copper conduction tube is the starting screen of the whole capacitance screen, and it is usually called zero screens.

(3) The capacitor core is the main insulation of the bushing, which bears the system voltage. It is composed of an aluminum foil with a semiconductor layer on the edge (electrode plate) and interscreen insulating medium winding on the electric conductive tube to form multilayer concentric cylindrical capacitor. After being fixed, these series capacitors form an integral capacitor core. 
Interscreen insulating medium in the capacitor core is cable papers (thickness $0.08 \mathrm{~mm}$; breakdown strength $7 \mathrm{kV} / \mathrm{mm}$ ), and the steam of silicone oil (or high quality transformer oil) is used for hydrophobic and impregnated treatment of the cable paper. Because the cellulose molecules of the cable paper are covered by oil molecules, the gap in the cellulose is filled with oil molecules. The electrical strength of the treated cable paper is improved (the short-time electrical strength is about $100 \mathrm{kV} / \mathrm{mm}$ ), and the hydrophilicity and water absorbability are greatly reduced.

(4) The middle flange of the bushing is usually equipped with measuring terminals and voltage taps. The measuring terminal is a copper strip about $0.3 \mathrm{~mm}$ thick and $50 \mathrm{~mm}$ wide, which is involved in the capacitance screen from the outer layer of the capacitor core. After the capacitive core is machined, a small window is dug to expose the copper strip. Then solder the soft copper stranded wire on the copper strip and connect it with the inner guide rod of the small bushing, and lead through the insulating bushing. The capacitance screen is mainly used to measure dielectric loss angle and capacitance of capacitance bushing.

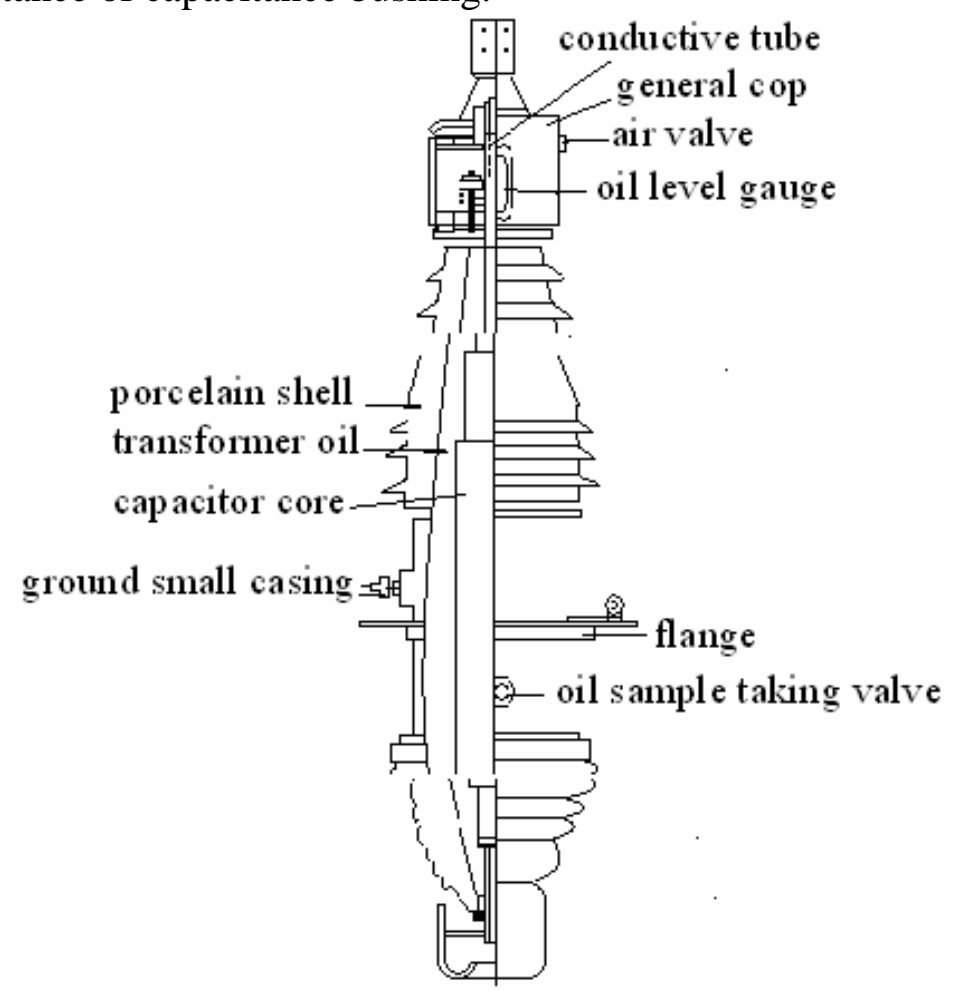

Fig. 1. Structure of oil-paper capacitive bushing

In the long run, the bushing not only has to bear the long-term maximum working voltage, but also tolerates all kinds of potential over-voltage. Deterioration of insulation medium, wetting and partial discharge will also occur on the bushing itself. The upper and lower porcelain sleeve parts of the bushing will be damaged by the material problem of the porcelain sleeve, the crack damage during transportation, the destruction of the external force during installation and the powerful mechanical force when the transformer outlet short circuit. Because of these reasons, bushing defects are unavoidable.

\section{Bushing Accident}

The main transformer substation was changed to SZ11-31500/66, and the wiring group YN, d11, manufactured in July 2015. It was put into operation in 2015, and the chromatographic tracking test was carried out according to Regulations of Condition-Based Maintenance \& Test for Electric Equipment regulations after puts into operation. On December 15th, 2017, the main transformer changed to light gas. Through chromatographic analysis, all kinds of gas had been found to increase, of which $\mathrm{H}_{2}, \mathrm{CH}_{4}, \mathrm{C}_{2} \mathrm{H}_{2}$, total hydrocarbon $(\mathrm{C} 1+\mathrm{C} 2)$ and other gases increased greatly, the total hydrocarbon exceed the specified value of $150 \mathrm{mu} \mathrm{L} / \mathrm{L}$. The chromatographic tracking test data is 
shown in Table II.

Table II Chromatographic tracking test data content $(\mu \mathrm{L} / \mathrm{L})$

\begin{tabular}{lcccccccccc}
\hline Position & $\mathrm{CH}_{4}$ & $\mathrm{C}_{2} \mathrm{H}_{4}$ & $\begin{array}{c}\mathrm{C}_{2} \mathrm{H} \\
6\end{array}$ & $\mathrm{C}_{2} \mathrm{H}_{2}$ & $\begin{array}{c}\text { Total } \\
\text { hydrocarbon }\end{array}$ & $\mathrm{H}_{2}$ & $\mathrm{CO}$ & $\mathrm{CO}_{2}$ & Time & Remarks \\
\hline Noumenon & 1.34 & 0.65 & 0.23 & 0.35 & 2.57 & 1 & 24 & 160 & 2015.11 .25 & $\begin{array}{l}\text { Before put into } \\
\text { operation }\end{array}$ \\
\hline Noumenon & 12.51 & 0.93 & 0.87 & 0.08 & 14.39 & 38 & $\begin{array}{c}32 \\
5\end{array}$ & 483 & 2017.3 .3 & Routine test \\
\hline Noumenon & 16.21 & 1.68 & 1.52 & 0.79 & 20.20 & 53 & $\begin{array}{c}43 \\
2\end{array}$ & 627 & 2017.12 .14 & Light gas alarm \\
\hline Noumenon & 31.45 & 25.15 & 2.66 & 70.38 & 129.64 & $\begin{array}{c}12 \\
7\end{array}$ & $\begin{array}{c}50 \\
7\end{array}$ & 726 & 2017.12 .15 & Monitor \\
\hline Noumenon & 33.22 & 26.79 & 2.82 & 73.23 & 136.07 & $\begin{array}{c}14 \\
7\end{array}$ & $\begin{array}{c}53 \\
9\end{array}$ & 771 & 2017.12 .18 & $\begin{array}{l}\text { Low energy } \\
\text { discharge }\end{array}$ \\
\hline \hline
\end{tabular}

\subsection{Accident nature determination}

At present, the many years experience shows that the three-ratio method can be more effective in judging the nature of the internal fault of the transformer in the method of judging the relative content of the characteristic gas. The results of the three ratios are as follows.

$$
\begin{aligned}
& \frac{\mathrm{CH}_{4}}{H_{2}}=\frac{33.22}{147}=0.23 \\
& \frac{C_{2} H_{4}}{C_{2} H_{6}}=\frac{26.79}{2.82}=9.5 \\
& \frac{C_{2} H_{2}}{C_{2} H_{4}}=\frac{73.23}{26.79}=2.73
\end{aligned}
$$

The three-ratio method is coded as "2, 0, 2" and is a low energy discharge fault.

\subsection{Determine the defect site}

There are four kinds of possible defects in the occurrence of low-energy discharge faults in the main transformer. Low energy discharge fault caused by bushing; low energy discharge fault caused by inter-turn short-circuit of windings; low energy discharge fault caused by multi point grounding of main transformer core; the fault of the arc discharge caused by the tap-changing operation. The following out method is used to find the fault location.

\subsubsection{Use of routine test methods}

The conventional test method is DC resistance test, variable ratio test and no-load test. The transformer brand and test data are shown in Table III, Table IV and Table V

Table III Transformer brand

\begin{tabular}{llll}
\hline & \multicolumn{3}{c}{ Equipment parameters } \\
\hline Model & SZ11-20000/66 & Rated capacity (kVA) & 20000 \\
\hline Rated voltage ratio & $66 \pm 8 \times 1.25 \% / 11$ & Rated current (A) & $175 / 1049.7$ \\
\hline Connection group & YNd11 & Cooling mode & ONAN \\
\hline $\begin{array}{l}\text { Short circuit } \\
\text { impedance(\%) }\end{array}$ & - & No-load current(\%) & 0.229 \\
\hline $\begin{array}{l}\text { Rated frequency } \\
\text { (HZ) }\end{array}$ & 50 & Date of production & 2008.12 \\
\hline Product number & 431 & Manufacturer & Xin Tai \\
\hline \hline
\end{tabular}


Table IV Variable ratio test

\begin{tabular}{cccc}
\hline \hline \multirow{2}{*}{$\begin{array}{c}\text { Tap changing } \\
\text { switch position }\end{array}$} & AB/ab & High voltage / Low voltage \\
\cline { 2 - 4 } & Error & BC/bc & CA/ca \\
Error & 0.15 \\
\hline 2 & 0.20 & 0.21 & 0.17 \\
\hline 3 & 0.23 & 0.22 & 0.28 \\
\hline 4 & 0.13 & 0.11 & 0.15 \\
\hline 5 & 0.15 & 0.15 & 0.08 \\
\hline 6 & 0.09 & 0.11 & 0.15 \\
\hline 7 & 0.12 & 0.13 & 0.27 \\
\hline 8 & 0.08 & 0.08 & \\
\hline $\begin{array}{c}\text { Connection group o } \\
\text { f three-phase }\end{array}$ & YNd11(consistent with the brand of transformer) \\
\hline \hline
\end{tabular}

Table V DC resistance test

\begin{tabular}{|c|c|c|c|c|c|c|}
\hline Winding & $\begin{array}{l}\text { Tap changing } \\
\text { switch position }\end{array}$ & Phase & $\begin{array}{c}\text { Factory value } \\
(\Omega)\left(30^{\circ} \mathrm{C}\right)\end{array}$ & $\begin{array}{c}\text { Measured } \\
\text { value }(\Omega)\end{array}$ & $\begin{array}{l}\text { Conversion to } \\
\text { factory } \\
\text { temperature } \\
(\Omega)\end{array}$ & $\begin{array}{c}\text { Initial value } \\
\text { difference(\%) }\end{array}$ \\
\hline \multirow{21}{*}{$\begin{array}{l}\text { High } \\
\text { voltage } \\
\text { side }\end{array}$} & \multirow{3}{*}{2} & $A(A-B)$ & 0.4434 & 0.4435 & 0.4435 & 0.02 \\
\hline & & $B(B-C)$ & 0.4443 & 0.4444 & 0.4444 & 0.02 \\
\hline & & $C(C-A)$ & 0.4459 & 0.4460 & 0.4460 & 0.02 \\
\hline & \multirow{3}{*}{3} & $A(A-B)$ & 0.4356 & 0.4358 & 0.4358 & 0.05 \\
\hline & & $\mathrm{B}(\mathrm{B}-\mathrm{C})$ & 0.4361 & 0.4363 & 0.4363 & 0.05 \\
\hline & & $C(C-A)$ & 0.4378 & 0.4379 & 0.4379 & 0.02 \\
\hline & \multirow{3}{*}{4} & $A(A-B)$ & 0.4279 & 0.4278 & 0.4278 & -0.02 \\
\hline & & $\mathrm{B}(\mathrm{B}-\mathrm{C})$ & 0.4281 & 0.4282 & 0.4282 & 0.02 \\
\hline & & $C(C-A)$ & 0.4296 & 0.4298 & 0.4298 & 0.05 \\
\hline & \multirow{3}{*}{5} & $\mathrm{~A}(\mathrm{~A}-\mathrm{B})$ & 0.4197 & 0.4198 & 0.4198 & 0.02 \\
\hline & & $\mathrm{B}(\mathrm{B}-\mathrm{C})$ & 0.4201 & 0.4202 & 0.4202 & 0.02 \\
\hline & & $\mathrm{C}(\mathrm{C}-\mathrm{A})$ & 0.4217 & 0.4219 & 0.4219 & 0.05 \\
\hline & \multirow{3}{*}{6} & $\mathrm{~A}(\mathrm{~A}-\mathrm{B})$ & 0.4124 & 0.4122 & 0.4122 & -0.05 \\
\hline & & $\mathrm{B}(\mathrm{B}-\mathrm{C})$ & 0.4122 & 0.4122 & 0.4122 & 0.00 \\
\hline & & $\mathrm{C}(\mathrm{C}-\mathrm{A})$ & 0.4138 & 0.4139 & 0.4139 & 0.02 \\
\hline & \multirow{3}{*}{7} & A(A-B) & 0.4040 & 0.4042 & 0.4042 & 0.05 \\
\hline & & $B(B-C)$ & 0.4041 & 0.4043 & 0.4043 & 0.05 \\
\hline & & $C(C-A)$ & 0.4066 & 0.4067 & 0.4067 & 0.02 \\
\hline & \multirow{3}{*}{8} & $A(A-B)$ & 0.3965 & 0.3966 & 0.3966 & 0.03 \\
\hline & & $\mathrm{B}(\mathrm{B}-\mathrm{C})$ & 0.3963 & 0.3964 & 0.3964 & 0.03 \\
\hline & & $\mathrm{C}(\mathrm{C}-\mathrm{A})$ & 0.3978 & 0.3980 & 0.3980 & 0.05 \\
\hline \multirow{3}{*}{\multicolumn{2}{|c|}{ Low voltage side }} & $\mathrm{a}(\mathrm{c}-\mathrm{a})$ & 0.01708 & 0.01700 & 0.01700 & -0.47 \\
\hline & & $\mathrm{b}(\mathrm{b}-\mathrm{c})$ & 0.01702 & 0.01696 & 0.01696 & -0.35 \\
\hline & & $C(c-a)$ & 0.01705 & 0.01699 & 0.01699 & -0.35 \\
\hline
\end{tabular}

No-load test: The measured no-load current is $2.51 \mathrm{~A}$, and the no-load loss is $16.826 \mathrm{~kW}$. There is no obvious change compared with the test value of the factory.

The data of these three sets of conventional tests on transformer are in conformity with the regulations. No abnormality of the data proves that the low energy discharge fault has nothing to do with the winding of the main transformer. In this way, "low energy discharge fault caused by inter-turn short-circuit of windings" is expelled and "the fault of the arc discharge caused by the tap-changing operation" is also discharged.

\subsubsection{Using Rogers method}

As shown in Table 2, Rogers method is expressed as. 


$$
\begin{aligned}
& \frac{\mathrm{CH}_{4}}{H_{2}}=\frac{33.22}{147}=0.23 \\
& \frac{C_{2} H_{6}}{C_{4}}=\frac{2.88}{33.22}=0.087 \\
& \frac{C_{2} H_{4}}{C_{2} H_{6}}=\frac{26.79}{2.82}=9.5 \\
& \frac{C_{2} H_{2}}{C_{2} H_{4}}=\frac{73.23}{26.79}=2.73
\end{aligned}
$$

The Rogers method is coded as "0, 0, 2, 2", belongs to low-energy discharge, and initially determine the discharge that does not belong to the iron core. Then the iron core insulation resistance test is carried out. The insulation resistance of the iron core to the earth is $1200 \mathrm{M} \Omega$ (greater than regulation standard $100 \mathrm{M} \Omega$ ). From the test results, it is found that there is no defect in the insulation resistance of the iron core. As a result, the "low energy discharge fault caused by multi point grounding of main transformer core," was discharged.

\section{Core Inspection}

On December 21st, 2017, the main transformer was checked at the site for hanging cores. After the core was removed, cracks were found in the lower porcelain sleeve of the bushing. Up and down through cracks occurred along the circumference of $1 / 3$ of the area. The damaged part of the porcelain sleeve falls off, and the exposed surface of the corresponding insulating core had a large area of significant carbon black discharge traces. There was a large amount of ice in the upper cavity of the sleeve uniform pressure ball, as shown in Figure 2.

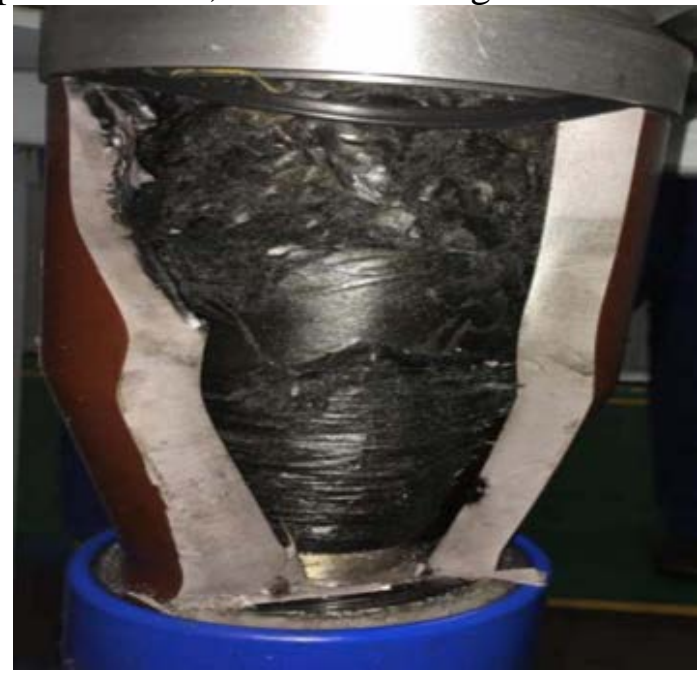

Fig. 2. Damage of the lower porcelain sleeve of the bushing

According to the observation, there was icing phenomenon on the upper part of the uniform pressure ball in the bushing oil, which was caused by the water flowing out of the bushing after the damage of the lower porcelain sleeve. The direct cause of bushing discharge and cracking of lower porcelain sleeve was water inflow inside the bushing. Therefore, it was the key point to analyze whether there was a sealing problem in the bushing. In addition, no apparent leakage of oil was found in the above part of the flange in the bushing appearance observation. It was determined that there was no leakage of water in the parts below the oil surface in normal condition (the oil level window range of the oil gathering box) of the bushing.

According to the analysis conclusions in the appearance inspection, there was no leakage of water in the parts below the oil surface in normal condition of the bushing. Therefore, all sealing 
points in the oil surface above were further examined and analyzed. There are 3 sealing positions involved in the parts above the oil surface. (1) Between the bushing connection seat and the oil collecting box cover. (2) Between the oil collecting box cover and oil collecting box. (3) The drain plug of the head of the bushing. The inspection had shown that the fasteners between the bushing connection seat and the oil collecting box cover, the oil collecting box cover and the oil collecting box were not loose, and the sealing gaskets were intact. However, it had been found that the drain plug of the head of the bushing was not effective in fastening (the plug should be loosened by hand), the sealing performance was not enough, and there were traces of water seepage in the interior of the bushing, so as to judge it should be the leakage point of the bushing. As shown in Figure 3.

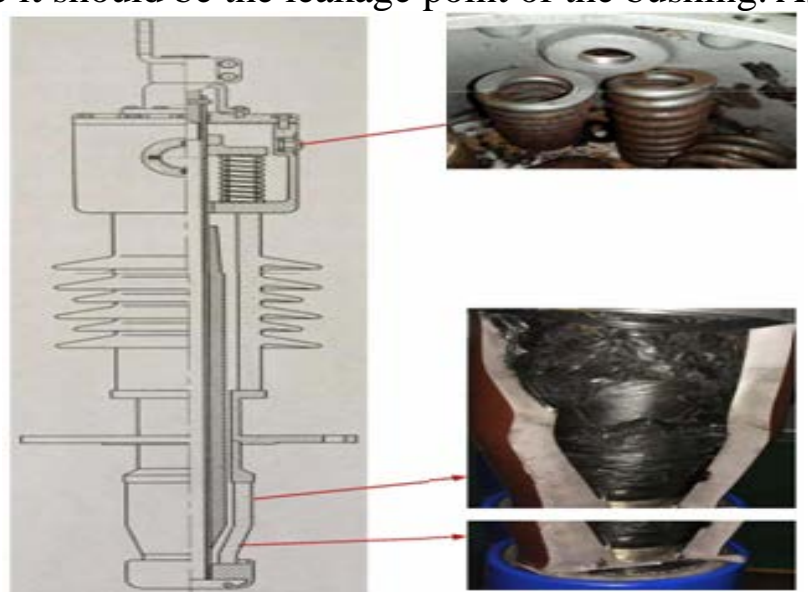

Fig.3. Bushing failure position

Through the analysis of the bushing operation and the inspection of the hang iron core, it is believed that the root cause of the fault is that the gas plug can not be tightened during the operation of the gas plug of the bushing, so that the sealing performance of the bushing is destroyed. When the ambient temperature is low, the transformer oil in the bushing forms a micro negative pressure state due to the characteristics of thermal expansion and cold contraction. Steam near the plug of the bushing head and rain and snow are sucked into the bushing and flow along the inner wall to the tail of the bushing. Because the bushing belongs to the short tail bushing, the insulation in the oil is relatively short. Under the condition of water accumulation in the tail of the bushing, the water content in the oil is increased and the insulation property is reduced. The bushing is discharged along the surface of the capacitor core under the operating voltage, resulting in acetylene, and resulting in cracking of lower porcelain sleeve.

\section{Conclusions}

The bushing is the main insulation device outside the main transformer box. The lead wire of the transformer winding must pass through the insulation bushing to insulate between the lead wire and the lead wire and the transformer shell, and also functions as a fixed lead wire. At the same time, bushing is one of the most important components of transformers. The bushing is also a current carrying element. The transformer will run through load current and short-time overcurrent for a long time. Therefore, the bushing must have good thermal stability to withstand transient overheating during short circuit. Due to the very small percentage of bushing accidents in the main transformer accidents, especially the porcelain bushing damage accidents of the bushings, the faults of the lower bushings of the bushing bushings will leave valuable experience and methods for the future.

\section{References}

[1] Cao Jianzhong. Electrical test [M]. Beijing: China Power Press,2005.

[2] Chen Huagang. Power equipment preventive test methods and diagnostic techniques [M]. 
Beijing: Science and Technology Press, 2001.

[3] Yin Kening. Transformer design principle [M]. Beijing: China Power Press, 2003.

[4] Zhang Jiaxiang. Transformer coil wave process [M]. Beijing: Water and Power Press, 1983.

[5] Zhu Yingjie. Main insulation design and related problems of transformer design principle. Transformer. 1979. 